\title{
A espacialidade dos períodos na relação espaço-tempo
}

\section{The Spatiality of Periods in the Space-Time Relationship \\ La espacialidad de los períodos en la relación espacio-tiempo}

Leonardo Luiz Silveira da Silva ${ }^{1}$ https://orcid.org/0000-0002-7082-529X

Alfredo Costa ${ }^{2}$ https://orcid.org/0000-0002-1735-6711

Larissa Santos Rocha da Silva ${ }^{3}$ https://orcid.org/0000-0002-6105-9204

\footnotetext{
${ }^{1}$ IFNMG campus Salinas, Salinas, Minas Gerais, Brasil, leonardo.silveira@ifnmg.edu.br.

${ }^{2}$ IFNMG campus Pirapora, Pirapora, Minas Gerais, Brasil, alfredo.costa@ifnmg.edu.br.

${ }^{3}$ IFNMG campus Salinas, Salinas, Minas Gerais, Brasil, lariflorestal@hotmail.com .
}

Recebido em: 09/08/2021

Aceito para publicação em: 30/09/2021

\section{Resumo}

O artigo versa sobre um tópico residente na interface espaço-temporal. Assim como as regiões geográficas, períodos se oferecem ao escrutínio do tempo e espaço. Transitando por uma discussão epistemológica, é objetivo deste artigo refletir sobre a espacialidade dos períodos, propondo vê-los como redes, espaços imaginados e arbitrariedades. Adota-se como metodologia uma estratégia discursiva que nega a abordagem apartada entre ideias e materialidade, ainda que veja sua face de maior tangibilidade na abordagem dos períodos por meio de relações, seja pela duração temporal ou extensão espacial. Conclui-se que os períodos, quando vistos sob o prisma das relações espaciais, são caricaturas da realidade que compõem uma estratégia comunicativa de princípio homogeneizador que, por essência, é oblíquo.

Palavras-chave: Períodos; Redes; Relações; Espacialidade; Espaços imaginados.

\begin{abstract}
This article focuses on a topic of the space-time interface. Like geographic regions, periods are open to the scrutiny of time and space. Moving through an epistemological discussion, it aims to reflect on the spatiality of the periods, proposing to see them both as networks, as imagined spaces and as arbitrariness. Methodologically, it is based on a discursive strategy that denies the separate approaches between ideas and materiality, even though the approach to periods through relations - whether by temporal duration or spatial extension - is the one that provides the best adherence. We conclude that periods, when viewed from the perspective of spatial relationships, are caricatures of reality that take part in communicative strategies with an oblique homogenizing principle.
\end{abstract}


Keywords: Periods; Networks; Relations; Spatiality; Imagined spaces.

\section{Resumen}

El artículo trata sobre un tema que reside en la interfaz espacio-temporal. Al igual que las regiones geográficas, los períodos se ofrecen al escrutinio del tiempo y el espacio. A través de una discusión epistemológica, este artículo reflexiona sobre la espacialidad de los períodos, proponiendo verlos como redes, espacios imaginados y arbitrariedades. Se adopta una estrategia discursiva como metodología que niega el enfoque separado entre ideas y materialidad, aunque ve su mayor tangibilidad en el acercamiento a períodos a través de relaciones, ya sea por duración temporal o extensión espacial. Se concluye que los períodos, vistos desde la perspectiva de las relaciones espaciales, son caricaturas de la realidad que componen una estrategia comunicativa con un principio homogeneizador que es oblicuo.

Palabras clave: Períodos; Redes; Relaciones; Espacialidad; Espacios imaginados.

\section{Introdução}

Períodos são muito problematizados na reflexão historiográfica; o mesmo não pode ser dito em âmbito geográfico. Aprioristicamente, este fato apresenta-se como um contrassenso sustentado pelo caráter indissociável da relação espaço-tempo. A ideia de que períodos possuem espacialidade, assim como a concepção de que certas porções do espaço exibem períodos, denotam uma concatenada reflexão espaçotemporal que nem sempre se apresenta simplória; diferentemente, esta reflexão, feita de forma descuidada, pode nos levar a generalizações indevidas.

Mesmo que determinados estudos geográficos não possam ser considerados propriamente pertencentes ao campo da geografia histórica, o geógrafo, em muitos casos, incorpora o tempo em sua análise (CORRÊA, 2016), afinal, a dimensão temporal incide na experiência do espaço (OLIVEIRA, 2013). Em linha similar, Haesbaert (2021) argumenta que espaço e tempo não podem ter existência independente, separada dos processos que os produzem.

A concepção do espaço e paisagem como categorias dinâmicas temporalmente evidenciam a necessidade da problematização temporal por parte do geógrafo. 
Santos (2012) salienta que a paisagem é "história congelada", mas que participa da "história viva". Seria história congelada porque se constitui como uma fotografia captada em um dado momento do tempo. Participaria da história viva porque as suas formas realizariam, no espaço, as funções sociais. São estas funções sociais e a dinâmica da natureza que garantem a efemeridade da paisagem. Barbara Bender prefere se referir à paisagem como um tempo em materialização: assim como o tempo, a paisagem está em constante movimento (BENDER, 2002), inexorável no seu dinamismo. O tempo atomístico é implacável quanto à atuação sobre os materiais e objetos que compõem a paisagem. As formas das coisas são delineadas pelo fluxo dos materiais ao longo do tempo. Assim como a Terra propriamente dita, a superfície de todo sólido é uma crosta, um frame captado de um dinâmico movimento degenerativo e/ou incorporador (INGOLD, 2007).

Refletir sobre a espacialidade do período é penetrar incisiva e epistemologicamente na zona de congruência da história e da geografia. As formas de elaborar esta reflexão acabam por trazer, necessariamente, a irresistível noção de que a história sem o espaço e a geografia sem o tempo são disciplinas mancas; em uma analogia, seria como vislumbrar dimensões diferentes em um mesmo plano. É objetivo deste artigo problematizar, a partir de uma abordagem essencialmente epistemológica, a interface entre a noção de períodos e o espaço geográfico, tendo como base a possibilidade de ver os períodos como redes, como espaços imaginados e como arbitrariedades. Destacamos que nossas considerações partem da premissa de que mente e matéria, materialidade e imaterialidade são indiscerníveis (WALTON, 1995; INGOLD, 1993; CAETANO; BEZZI, 2011; BERQUE, 2012, 2017; SILVA; GIL FILHO, 2020; SILVA, 2020), pois “a realidade vai além do material, ao mesmo tempo retornando a ele também" (BERQUE, 2012, p.7). Assim, “cada forma simbólica possui um papel de sentido e significado nessa estruturação, sendo parte de um universo que é constituído pelo material e imaterial" (SILVA; GIL FILHO, 2020, p.165). Acreditamos que o idealismo extremado não é a resposta para a posição exclusivamente materialista da leitura do espaço. 


\section{Breve observação sobre a interface espaço-tempo}

A importância da interface espaço-temporal foi explorada por Derwent Whittlesey (1929) na primeira metade do século XX. O conceito que cunhou na ocasião, sequent occupance, refere-se justamente à possibilidade de analisar uma mesma área a partir de períodos que seriam definidos por padrões mais ou menos homogêneos nas interrelações entre o homem e o meio. Richard Elwood Dodge (1938), intérprete de Whittlesey, reflete sobre a postura do geógrafo frente à ideia do sequent occupance: “Em nome do esclarecimento, o geógrafo deve pontuar as mudanças sistematicamente, de modo a compreendê-las como um reflexo das relações geográficas também em mudança" (DODGE, 1938, p.236, tradução nossa). Whittlesey (1929) busca ainda relativizar o rigor de sua periodização ao vislumbrar a possibilidade de etapas de transição entre períodos. Em suas palavras: “A visão da geografia como uma sucessão de estágios de ocupação humana estabelece a genética de cada estágio em relação ao seu predecessor" (WHITTLESEY, 1929, p.162, tradução nossa). Assim, a sequent occupance possibilita o estabelecimento de comparações geográficas ao longo do tempo.

Uma das chaves das conexões envolvendo a história e a geografia e, portanto, o tempo e o espaço, são justamente os processos. Se a geografia - contrariando a etimologia da palavra - não é uma mera descrição do espaço (pois inclui a explicação sobre a distribuição, comparação, frequência e inter-relação entre fenômenos), o tempo torna-se um natural partícipe da análise geográfica.

As relações entrecruzadas do tempo e do espaço vão além da geografia e da história: "o espaço e o tempo são alvo de preocupação de outros cientistas sociais tanto quanto são da geografia e da história" (BAKER, 1981, p.439, tradução nossa). $\mathrm{Na}$ mesma lógica destes autores, refletindo sobre as relações entre a geografia e a história, H. C. Darby (1953) abordou a "geografia que está por trás da história” e a "história por trás da geografia", destacando que não é possível desenhar uma linha 
separando as duas disciplinas, da mesma forma em que não é possível fixar uma data a partir de uma pesquisa geográfica para dizer que a partir dela estaremos falando de uma geografia histórica. John Langton (1988) também reforça a ideia ao pensar na geografia como uma ciência das relações espaciais e, nesse sentido,

à medida que as relações descritas no presente e no passado só podem ser relatadas e tornadas inteligíveis a partir da referência do seu desenvolvimento ao longo do tempo, toda geografia humana deve ser histórica e toda a história deve ser sobre um lugar, e, portanto, ser geográfica (LANGTON, 1988, p.345, tradução nossa).

A perspectiva de que toda a geografia é histórica coloca em questão a necessidade de existência das subdisciplinas "geografia histórica" [historical geography], "história geográfica [geographical history]" ou ainda geografia humanista histórica ${ }^{4}$ humanistic historical geography]. A subdisciplina geografia histórica deve a sua consolidação aos nomes de A. H. Clark nos Estados Unidos e a Clifford Darby no Reino Unido, em uma época em que o neopositivismo era muito influente no seio da geografia $^{5}$ (anos 1950 até os anos iniciais da década de 1960). Darby assim definiu a geografia histórica em meados do século XX:

o termo "geografia histórica" tem sido identificado como uma abordagem na qual os dados são históricos, mas o método de análise é geográfico. O propósito do geógrafo histórico, de acordo com esta visão, é reconstruir a geografia de tempos pretéritos (DARBY, 1953, p.4, tradução nossa).

Nota-se, todavia, diferenças quanto ao entendimento do escopo da disciplina, bem como quanto à sua nomenclatura, o que leva a alguns a considerar que geografia histórica e história geográfica são subdisciplinas diferentes. Craig, Currie e Joy (2001), por exemplo, utilizaram a expressão história geográfica para se referir às relações entre a história geológica de uma região e o endemismo de uma espécie de inseto. Contudo, é possível encontrar referências com abordagens distintas sobre o termo. Da mesma forma, não há “consenso sobre o que seja a geografia histórica,

\footnotetext{
4 Richard Dennis (1983) sugeriu o nome "geografia humanista histórica" para o subcampo do conhecimento no qual os métodos humanistas podem ser usados para interpretar "paisagens tradicionais" (DENNIS, 1983, p.591).

${ }^{5}$ A geografia histórica emergiu, parcialmente, como uma reação à visão de que a geografia se constituía como uma ciência espacial (HARRIS, 1991).
} 
apesar de existir uma concordância importante sobre o seu significado" (BAKER, 2007, p.344, tradução nossa), que vai ao encontro com a definição que Darby (1953) apresentou.

Vale destacar que o termo "história geográfica" é menos comum do que geografia histórica. Apesar da posição do adjetivo e do substantivo indicar que "história geográfica" é um braço da geografia e "geografia histórica" um braço da história, há um registro muito variado do uso destes termos que se afasta desta lógica (BAKER, 2007). Essa problemática ilustra a dificuldade na organização de uma pesquisa ou mesmo na elaboração textual que remeta à interface espaço temporal, fazendo com que "em princípio, a diferença entre a história geográfica e a geografia histórica seja nublada" (BAKER, 2007, p.354, tradução nossa). Ilustrando esta questão, J. K. Wright (1960) listou em um artigo inúmeras possibilidades de abordagens que entrelaçam a geografia e a história, evidenciando-nos a ampla dimensão que justifica as confusões semânticas sobre a(s) subdisciplina(s) que se preocupam com a interface histórico-geográfica.

\section{Períodos como redes}

A reificação de ideias e palavras que representam coletividades passa pelo constrangimento de suprimir as diferenças identitárias. Thompson (1987) rejeita a reificação da classe ${ }^{6}$, alegando que a mesma é uma relação e, desta forma, "como qualquer outra relação, é algo fluído que escapa à análise ao tentarmos imobilizá-la num dado momento e dissecar sua estrutura" (THOMPSON, 1987, p.9-10). Entretanto, ao analisar a tensão envolvendo identidade e representação coletiva, o autor assim salienta:

Se detivermos a história num determinado ponto, não há classes, mas simplesmente uma multidão de indivíduos com um amontoado de experiências. Mas se examinarmos esses homens durante um período adequado de mudanças sociais, observaremos padrões em suas relações, suas ideias e suas instituições. A classe é definida pelos

\footnotetext{
${ }^{6}$ Thompson alegou, em 1987, que em muitos textos marxistas da época era possível verificar esta abordagem da classe reificada, que julga inadequada.
} 
homens enquanto vivem sua própria história e, ao final, esta é a sua única definição (THOMPSON, 1987, p. 11-12).

A argumentação de Thompson é coerente com a sua ideia de classe enquanto relação, pois esta se dá no tempo em movimento. As relações, constituídas pelas escolhas dos homens em meio aos laços de poder espaço-temporalmente instáveis, são suficientemente efêmeras para desconstruir as classes reificadas (SILVA; COSTA, 2020). A crença na existência da classe, todavia, ajuda a compreender o arranjo de certas relações, o que dificulta a separação entre as dimensões materiais e imateriais. Estando de acordo com a ideia de Thompson, pensamos que a cultura e a raça, dentre outros agrupamentos coletivos que transitam entre ideias e concretude, possam ser pensadas como relações. Acreditamos que as relações sejam elos de interseção entre a mente e a matéria.

Propomos que o estabelecimento de períodos é tão arbitrário como a definição do que seja uma classe (THOMPSON, 1987), nação (ANDERSON, 2008), cultura (SILVA; COSTA, 2018) ou região (WILCOCK, 1954; HARTSHORNE, 1978; WISHART, 2004; AGNEW, 1999, 2013). Se a definição de um período histórico passa pela análise de processos relativamente homogêneos que apresentam limitado alcance espacial (afinal, é difícil considerar, por exemplo, o período feudal na história brasileira pré-colonial), os períodos podem ser vistos como relações, que se dão entre fixos e fluxos em um ambiente de rede. Neste particular, apresenta-se útil o conceito de afeto, bastante utilizado pelas teorias não-representacionais, pois tal conceito tem a capacidade de contemplar o entrelace entre o plano da materialidade e da imaterialidade. Se as relações são faces tangíveis das redes, os afetos vão além, penetrando no campo das intencionalidades e emoções, podendo resultar em ações mensuráveis. Steven Pile destaca que o afeto exibe uma via de mão dupla, pois "demonstra a capacidade transpessoal que um corpo tem de ser afetado e de afetar (como resultado daquilo que vivencia)" (PILE, 2010, p.8, tradução nossa), argumento endossado por Ben Anderson (2016). Deste modo, o afeto não é simplesmente 
pessoal ou interpessoal: é transpessoal, à medida que se desenha no relacionamento de muitos corpos. Ipso facto, o afeto se expressa ao mesmo tempo com e entre os corpos. É importante destacar que o afeto também envolve relações entre agentes humanos e não-humanos.

A espacialidade das relações evidencia processos, que, vistos a partir de lentes diacrônicas, denunciam a vitalidade do status quo político-social, bem como o caráter do entrelace entre o homem e o espaço. Entre permanências, sucessões, durações, rupturas e descontinuidades das relações entre agentes humanos e não-humanos, períodos podem ser precisados (MARTINS, 2007). Da aurora ao ocaso do Brasil escravocrata, relações foram estabelecidas e dinamizadas; é mítico, contudo, considerar que as relações que revelam a escravidão possam ser representadas a partir de uma superfície sólida e contínua. As redes possuem a vantagem da representação reticular, mais realista no que tange à exibição das relações entre fixos e fluxos; em áreas de grande adensamento das relações, é costumaz a consideração acerca da solidez monolítica de processos, o que sempre suprime a representação das subversões identitárias, residindo neste fato a fragilidade da elaboração generalizadora. Nessas situações, a escala de análise deve ser ajustada para mitigar problemas.

\section{Períodos como espaços imaginados}

As generalizações são consequências do pensamento moderno. Ainda que a racionalidade - base do pensamento moderno - não seja sinônimo de descuido generalizador, a elaboração de teorias ou modelos aplicáveis em diversos contextos lhes confere um verniz de autenticidade científica. Do ponto de vista teórico, a denominada pós-modernidade nega o universalismo e a generalização que eram qualidades e procedimentos inerentes à modernidade. Há o questionamento quanto à existência de fronteiras rigorosas que dividem o saber em campos especializados (CORRÊA, 2000). Em oposição aos modernistas, há uma predominância do irracional que utiliza como ferramentas as formas, cores, imagens, metáforas e os sentidos, que 
são permanentemente reatualizados e reconstruídos. O modernismo busca uma verdade universal e repousar sobre a estabilidade do significado, usualmente por intermédio de um metadiscurso ou metanarrativa. $\mathrm{O}$ pós-modernismo, por conseguinte, assumiu a forma de uma revolta contra as rígidas convenções existentes sobre os métodos e linguagem (DEAR, 1988 e 1994; EAGLETON, 1998; ANDERSON, 1999; LEMOS, 1999; CORRÊA, 2000).

Desta forma, tradicionalmente os períodos foram tratados como mantras inquestionáveis, dotados de datas rígidas que marcaram sua aurora e ocaso, sem nenhuma preocupação com seu alcance espacial. As sequelas dessas elaborações têm se mantido; mesmo pesquisadores familiarizados com a interface espaço-temporal precisam estar atentos em suas elaborações para não transmitir, por meio do ato comunicativo, abertura para entendimentos ambíguos.

Christian Grataloup (2006) afirma que períodos precisam ser entendidos "regionalmente". Ao fazer esta afirmativa, o autor considera que os processos históricos que marcam determinados períodos, a rigor, ocorrem de forma mais clara em determinadas porções do espaço; a notoriedade de tais processos se caracteriza por ser portadora de uma intensidade que se dissipa de maneira espacialmente difusa e ilimitável. Nesse sentido, a ideia acerca de um período feudal, possui espacialidade.

As problematizações entre as relações entrecruzadas entre o espaço e a temporalidade não são novas. Mesmo no âmbito do determinismo geográfico no início do século XX, a partir de autores como Ellen Semple e Ellsworth Huntington, já existiam argumentações que defendiam o ponto de vista de que eventos históricos não podiam ser vistos da mesma forma em espaços diferentes (HUNTINGTON, 1937). Todavia, estes determinismos interpretavam a relação espaço-tempo a partir de grosseiras diferenças do quadro natural. Desde os avanços trazidos pelo difusionismo nos estudos antropológicos, tornou-se ponto pacífico que as relações entre o homem e o meio podem se tornar muito distintas mesmo entre ambientes naturais dotados de grandes semelhanças. Nesse sentido, o determinismo peca ao 
condicionar diferenças no quadro natural como linhas que demarcam distintos impactos dos eventos históricos sobre as sociedades.

Independentemente do relativismo que se aplica às relações espaço-temporais, os períodos sempre são espaços imaginados. É impensável considerar grandes superfícies processualmente homogêneas. Se a diversidade é o apanágio do espaço geográfico, seria mais justo representar espacialmente períodos como arquipélagos, ou reticularmente. Períodos, expressos como processos relativamente homogêneos que se manifestam espacialmente, sugerem fragmentação da representação espacial. Seria justo imaginar em um dado momento do tempo a Europa monoliticamente feudal?

Como desafio adicional está a passagem do tempo atomístico. O mosaico espacialmente fragmentado que compõe os núcleos relativamente homogêneos de processos (que nos permitem identificar períodos) não são imunes ao tempo. Singelas acelerações temporais colocam o mosaico em movimento, que tal como em um caleidoscópio, se rearranjam de forma muito complexa de ser compreendida globalmente.

Assim, os períodos são imaginados pela inviabilidade de uma representação fiel. As flexibilizações dos critérios de inclusão espacial em áreas supostamente pertencentes à égide do período são tamanhas que somente poderemos conceber um exercício de generalização arbitrária.

\section{Períodos como arbitrariedades}

Analisar os períodos como redes é a face aparentemente objetiva da determinação de intervalos de tempo; contudo, ae escolhas do pesquisador frente as fontes de pesquisa - necessárias para a compreensão das relações que constituem as redes - podem revelar novas arbitrariedades que penetram no campo da subjetividade analítica. José D’Assunção Barros (2005) recomenda que o recorte espaço-temporal do período seja definido a partir do conjunto de fontes disponíveis 
sobre o assunto que se quer investigar, postura coerente do ponto de vista da pesquisa metodologicamente flexível. Deixar que as fontes disponíveis definam o intervalo espaço-temporal da pesquisa, todavia, flerta com um risco: a variação espaço-temporal das fontes pode ser extrema, conduzindo o pesquisador a uma história universal que a própria abordagem particularista critica. Neste caso, a interferência da arbitrariedade do pesquisador pode novamente ser demandada.

A subjetividade também se apresenta em outro campo da abordagem dos períodos entendidos enquanto um conjunto de relações que se manifesta no espaço. É certo que as redes que revelam relações podem ter grande abrangência. Todavia, é possível identificar um ou mais nós relevantes, onde o volume dos fluxos bem como a difusão das relações se intensifica. A escolha de delimitar tais nós enquanto "centros nervosos" é mais uma arbitrariedade que revela a face subjetiva do período. E, ao mesmo tempo, sobrepõe a ideia de período à ideia de região. Logo, a compreensão dos períodos de tempo enquanto relações que se manifestam espacialmente não busca consagrar um resultado objetivo, quantificável. No entanto, do ponto de vista da análise espaço-temporal, é uma forma mais adequada de representação quando comparada às formas tradicionais de se conceber os períodos.

O que dizer então quanto ao desafio de transformar a ideia do período espacialmente representado em uma narrativa? A difícil tarefa de construção de uma narrativa histórica mediante o quadro de instabilidade do narrador e do próprio questionamento acerca da verdade histórica são motivos que inspiram David Lowenthal a argumentar que o passado é um país estrangeiro (LOWENTHAL, 2015). Roberto Lobato Corrêa - em franca sintonia com a perspectiva de Lowenthal salienta que "o passado pode ser visto como um texto incompleto, cuja leitura permite, mais do que o presente, interpretações diversas, possibilitando reconstruções adequadas às vicissitudes de cada momento e de cada grupo social" (CORRÊA, 2007, p.13). Karen E. Till (2001) acrescenta que o passado não existe de forma literal, sendo expresso como vestígios das ações do presente, que podem durar mais do que a nossa própria existência. A autora ainda diz que para a prática da 
geografia histórica é indispensável o exercício da empatia, pois se faz necessário se colocar em uma posição de interlocução problemática, seja por escrever ou falar de um tempo, evento ou local não vivido. Mesmo que o narrador tenha familiaridade com o objeto, por se tratar de um passado não muito distante ou de uma região geográfica familiar, os problemas associados à narrativa persistem.

Este assunto é abordado com profundidade pelo historiador norte-americano Hayden White, que refletiu sobre os eventos a partir da problemática que envolve a narrativa que os reportam. Em outra publicação, White (1984) argumenta que a narrativa é um modo de discurso, uma maneira de falar e, também, um produto confeccionado pela adoção de um modo de discurso. White rechaça a dicotomia entre a presença do "verdadeiro" e "falso" nas narrativas e sugere que as divergências sejam expressas em outra oposição: real versus imaginário. Ankersmit (2001) aponta as limitações da narrativa ao refletir sobre uma situação paradoxal que acomete os textos: "o texto não é transparente em relação ao passado, mas chama a atenção do leitor sobre si mesmo; ao fazer isto, obscurece o passado em si" (ANKERSMIT, 2001, p.159). Acrescenta ainda, em um argumento muito importante, que as narrativas não devem ser entendidas como relatos que se aproximam de uma história não contada (ANKERSMIT, 2010), que traria a verdade dos fatos. Este argumento rechaça a verdade histórica, reforçando a ideia de que somente existe a história "sob descrição", tal como preconizou Hayden White. Ankersmit (2010) destaca que as narrativas são representações e, como tal, assemelham-se às pinturas de paisagem que se destacam por dar ênfase àquilo que capturou a atenção do pintor, ou ainda, o que ele deseja ver.

Ana Maria Alonso (1988) acrescenta que as histórias (palavra aqui empregada no sentido de narrativas) são ideologicamente construídas. Constituíram-se como "representações do passado organizadas por esquemas interpretativos e estratégias discursivas que produzem "efeitos da verdade" (ALONSO, 1988, p.50, tradução nossa). David Wishart (1997), por sua vez, argumenta que a tradicional escrita histórica, pautada nas metanarrativas, era alicerçada pela crença de que o "passado 
real" poderia ser dimensionado por intermédio do relato. Nesse sentido, a validação de relatos era um mero exercício comparativo entre as formas discursivas que se apresentavam e o passado real. Entretanto, é plausível considerar que "o passado real não está disponível" (WISHART, 1997, p.116, tradução nossa), em um argumento similar ao trazido por Ankersmit (2010).

A natureza das narrativas, bastante problematizada na teoria da história, é outra face arbitrária da definição de períodos enquanto espaços. Assim, a arbitrariedade dos períodos espaciais se manifesta, pelo menos, nos seguintes âmbitos:

- Na seleção de fontes que ilustram processos relativamente homogêneos e respaldam a delimitação temporal e espacial dos períodos;

- Na delimitação espacial dos processos que o pesquisador julga como relativamente homogêneos, ou seja, na elaboração de regiões-período;

- Na natureza das narrativas.

\section{Considerações finais}

Neste artigo, refletimos sobre a noção de período, evidenciando a sua espacialidade, assim como fizeram Grataloup e Wishart. A nossa contribuição original reside na consideração dos períodos como redes, espaços imaginados e arbitrariedades. O ponto de partida é o entendimento dos períodos enquanto manifestações espaciais de processos relativamente homogêneos, mensurados a partir da ação entre agentes que, distribuídos espacialmente, arranjam um tecido composto por fixos e fluxos. É importante lembrar que as relações não expressam exclusivamente materialidades; são, do ponto de vista das relações de afeto, carregadas de entrelaçamentos entre o plano material e imaterial, ou seja, entre mente e matéria. Dialeticamente, as próprias relações estão em movimento, por também afetar os agentes envolvidos que, por sua vez, emanam e recebem novas relações. Esta é a explicação para que os períodos, vistos como manifestações espaciais, tenham dinamismo perene. 
A partir da ideia dos períodos compreendidos enquanto relações espaciais, concebemo-nos como espaços imaginados e arbitrariedades. Períodos são espaços imaginados por se tratarem de generalizações, caricaturas da realidade que ignoram suas próprias exceções a favor de uma estratégia comunicativa ou mesmo de descuidos quanto à essência diversificada do espaço. Períodos são arbitrariedades por serem definidos por intermédio da coleta de fontes que inclui as opções do descarte e inclusão de informações, fazendo com que a delimitação espacial do período seja uma questão de método/escolha. A arbitrariedade dos períodos ainda se manifesta por meio das narrativas, que nunca contam uma verdade histórica, mas trazem, assim como preconiza Hayden White, a história enviesada.

É importante percebemos que a periodização alude fortemente aos dilemas vivenciados pela regionalização, demonstrando-nos que a história depende do espaço, como a geografia do tempo.

\section{Referências}

AGNEW, John. Regions on the mind does not equal regions of the mind. Progress in Human Geography, v.23, i.1, p.91-96, 1999.

AGNEW, John. Arguing with regions. Regional Studies, v.47, n.1, p.6-17, 2013.

ALONSO, Ana Maria. The Effects of Truth: Re-Presentations of the Past and the Imagining of Community. Journal of Historical Sociology, v.1, n.1, p.33-57, 1988.

ANDERSON, Ben. Becoming and being hopeful: towards a theory of affect. Environmental and Planning D: Society and Space, v.24, p.733-752, 2016.

ANDERSON, Benedict. Comunidades Imaginadas. São Paulo: Companhia das letras, 2008.

ANDERSON, James. Ideology in Geography: An Introduction. Antipode, v.5, n.3, p.1-6, 1973.

ANDERSON, Perry. As origens da pós-modernidade. Rio de Janeiro: Jorge Zahar, 1999.

ANKERSMIT, Franklin Rudolf. Historiografia e pós-modernismo. Topoi, p.113-135, 2001.

ANKERSMIT, Frankiln Rudolf. Truth in History and Literature. Narrative, v.18, n.1, p.29-50, 2010.

BAKER, Alan R. H. An historico-geographical perspective on time and space and on period and place. Progress in Human Geography, v.5, i.3, p.439-443, 1981. 


\section{A espacialidade dos períodos na relação espaço-tempo \\ SILVA, L.L.S.da; COSTA, A.; SILVA, L.S.R. da}

BAKER, Alan R. H. "The dead don't answer questionnaires": Researching and writing historical geography. Journal of Geography in Higher Education, v.21, n.2, p.231-243, 1997.

BAKER, Alan R. H. Classifying Geographical History. The Professional Geographer, v.59, n.3, p.344-356, 2007.

BARROS, José D'Assunção. História, região e espacialidade. Revista de História Regional, v.10, n.1, p.95-129, 2005.

BENDER, Barbara. Time and landscape. Current Anthropology, v.43, aug-oct, p.103-112, 2002.

BERQUE, Augustin. Geogramas, por uma ontologia dos fatos geográficos. Geograficidade, v.2, n.1, p.4-12, 2012.

BERQUE, Augustin. A cosmofania das realidades geográficas. Geograficidade, v.7, n.2, p.416, 2017.

CAETANO, Jessica Nene; BEZZI, Meri Lourdes. Reflexões na geografia cultural: a materialidade e a imaterialidade da cultura. Sociedade \& Natureza, ano 23, n.3, p.453-466, 2011.

CORRÊA, Margarida Maria da Silva. A pós-modernidade e as atuais orientações da geografia humana. Boletim Goiano de Geografia, v.20, n.1-2, p.43-76, 2000.

CORRÊA, Roberto Lobato. Formas simbólicas e espaço: algumas considerações. Geographia, v.9, n.17, p.7-18, 2007.

CORRÊA, Roberto Lobato. O interesse do geógrafo pelo tempo. Boletim Paulista de Geografia, v.94, p.1-11, 2016.

CRAIG, Douglas A; CURRIE, Douglas C; JOY, Deirdre A. Geographical history of the central-western Pacific black fly subgenus Inseliellum (Diptera: Simuliidae: Simulium) based on a reconstructed phylogeny of the species, hot-spot archipelagoes and hydrological considerations. Journal of Biogeography, v.28, p.1101-1127, 2001.

DARBY, H. C. On the Relations of Geography and History. Transactions and Papers (Institute of British Geographers), n.19, p.1-11, 1953.

DEAR, Michael. The Postmodern Challenge: Reconstructing Human Geography. Transactions of British Geographers, new series, v.13, n.3, p.262-274, 1988.

DEAR, Michael. Postmodern Human Geography: A Preliminary Assessment. Erdkunde, v.48, n.1, p.2-13, 1994.

DENNIS, Richard. Rethinking historical geography. Progress in Human Geography, v.7, i.4, p.587-594, 1983.

DODGE, Richard Elwood. The interpretation of Sequent Occupance. Annals of the Association of American Geographers, v.28, n.4, p.233-237, 1938.

EAGLETON, Terry. As ilusões do pós-modernismo. Rio de Janeiro: Jorge Zahar, 1998.

GRATALOUP, Christian. Os períodos do espaço. Geographia, v. VIII, n.16, p.31-40, 2006. 
HAESBAERT, Rogério. Território e descolonialidade: sobre o giro (multi)territorial/de(s)colonial na "América Latina". Buenos Aires e Niterói: Clacso e Universidade Federal Fluminense, 2021.

HARRIS, Cole. Power, Modernity, and Historical Geography. Annals of the Association of American Geographers, v.81, n.4, p.671-683, 1991.

HARTSHORNE, Richard. Propósitos e natureza da Geografia. São Paulo: Hucitec Edusp, 1978.

HUNTINGTON, Ellsworth. Geography and History. The Canadian Journal of Economic and Political Science, v.3, n.4, p.565-572, 1937.

INGOLD, Tim. The temporality of the landscape. World Archaelogy, v.25, n.2, p.152-174, 1993.

INGOLD, Tim. Materials against materiality. Archaeological Dialogues, v.14, i.1, p.1-16, 2007.

LANGTON, John. The Two Traditions of Geography, Historical Geography and the Study of Landscapes. Geografiska Annaler, v.70, n.1, p.17-25, 1988.

LEMOS, Amalia Inés Geraiges. Geografia da modernidade e geografia da pós-modernidade. Geousp, v.3, n.1, p.27-39, 1999.

LOWENTHAL, David. The Past is a Foreign Country. New York: Cambridge University Press, 2015.

MARTINS, Élvio Rodrigues. Geografia e ontologia: o fundamento geográfico do ser. GEOUSP: Espaço e Tempo (Online), [S. 1.], v. 11, n. 1, p. 33-51, 2007.

OLIVEIRA, Lívia de. Sentidos de lugar e de topofilia. Geograficidade, v.3, n.2, p.91-93, 2013.

PILE, Steven. Emotions and affect in recent human geography. Transactions of the Institute of British Geographers, New Series, v.35, n.1, p.5-20, 2010.

SANTOS, Milton. A Natureza do Espaço. São Paulo: Edusp, 2012.

SILVA, Leonardo Luiz Silveira da. A geografia entre a materialidade e a imaterialidade. Geotemas, v.10, n.2, p.25-47, 2020.

SILVA, Leonardo Luiz Silveira da; COSTA, Alfredo. Cultura como comunidade imaginada: uma crítica à abordagem ontológica da cultura nos estudos geográficos. Geografias, v.16, n.1, p.27-41, 2018.

SILVA, Leonardo Luiz Silveira da; COSTA, Alfredo. O desconforto da região e das classes. Geousp: Espaço e Tempo, v.24, n.3, p.533-546, 2020.

SILVA, Márcia Alves Soares da; GIL FILHO, Sylvio Fausto. Sobre o conceito de espaço vivenciado: refletindo as espacialidades a partir das experiências emocionais. Geograficidade, v.10, n. especial, p.153-168, 2020.

THOMPSON, Edward. P. A formação da classe operária. Rio de Janeiro: Paz e Terra, 1987. 
TILL, Karen E. Fragments, Ruins, Artifacts, Torsos. Historical Geography, v.29, p.70-73, 2001.

WALTON, Judy R. How Real(ist) can you get? Professional Geographer, v.47, i.1, p.61-65, 1995.

WHITE, Hayden. The narrativization of Real Events. Critical Inquiry, v.7, n.4, p.793-798, 1981.

WHITE, Hayden. The Question of Narrative in Contemporary Historical Theory. History and Theory, v.23, n.1, p.1-33, 1984.

WHITTLESEY, Derwent. Sequent Occupance. Annals of the Association of American Geographers, v.19, n.3, p.162-165, 1929.

WILCOCK, A. A. Region and Period. Australian Geographer, v.6, n.3, p.39-40, 1954.

WISHART, David. The selectivity of historical representation. Journal of Historical Geography, v.23, n.2, p.111-118, 1997.

WISHART, David. Period and region. Progress in Human Geography, v.28, n.3, p.305-319, 2004.

WRIGHT, John Kirtland. Geography and history cross-classified. The Professional Geographer, v.12, n.5, p.7-10, 1960.

Autor 1: Pesquisa bibliográfica, elaboração do texto, discussão dos resultados. Autor 2: Elaboração do texto, revisão metodológica, discussão dos resultados. Autor 3: Análise final dos resultados e revisão do texto. 